\title{
Contribution to the knowledge of a microgrid. Smart Campus
}

\author{
D. Quiroga Alonso, M. Pérez Donsión. \\ Department of Electrical Engineering \\ E.T.S.I.I., Vigo University \\ Campus of Lagoas - Marcosende, 36310 Vigo (Spain) \\ Phone/Fax number:+0034 986 812685, e-mail: danielquirogaalonso@yahoo.es, donsion@uvigo.es
}

\begin{abstract}
From an analysis of electric energy consumption of different buildings of the University of Vigo, it has been designed the integration of a microgrid and its elements, distributed generation, energy storage, security and control systems and applications of a Smart Campus.

Distributed generation of electricity is based on the integration of renewable energy sources, especially solar photovoltaic and wind energies, aided by the installation of a hydrogen fuel cell, which is produced out of energetic overproduction of the aforementioned sources by two electrolyzers.
\end{abstract}

In order to avoid the consequences of randomness of wind and solar sources, an energy storage system has been installed. It stores hydrogen produced when overproduction takes place, in order to be able to transform it into electricity when power needs of the microgrid demand it, through a hydrogen fuel cell.

Generation and energy storage will be regulated by a security and control system, which will also be responsible for the management and integration of several apps of the Smart Campus.

Besides, the implementation in the microgrid of these different apps of the Smart campus, charging spots for electrical cars, parking management, and replacement of conventional lighting by an intelligent and independent system based on renewable energy will be taken into consideration in this study.

\section{Keywords}

Microgrid, distributed generation, energy storage, energy sustainability, Smart Campus.

\section{Introduction}

Built-in a natural setting, located $11 \mathrm{~km}$ from the urban area, we can find the University Campus of Vigo. The harmonious coexistence of numerous architectural works created by important contemporary figures such as Enric Miralles, César Portela, or Gabriel Santos Zas with the student and sporty atmosphere make this campus a site of significant academic and cultural interest.

This university campus is comprised of numerous faculties, research centres, and sports facilities. It consumes energy from the general electrical system, thus, becoming solely into a mere electricity consumer element.
Since 1997 [1], the electric distribution grid of the University Campus of Vigo has made use of a high voltage power line that crosses the campus. By means of a transformer substation located in the West area of the site, the high voltage energy supplied by the distribution company - Gas Natural Fenosa - is transformed into medium voltage energy. Then, it is transported through a line spread tangentially along the Southwest of the campus up to reach the different comsumer elements of the University Campus of Vigo.

The current communications network, which has undergone many variations since 1997 due to the incorrect conditions of the initial implementation, enables the University Campus of Vigo to have telephone connection in all the buildings, which are also connected to each other through an optic-fibre network.

The lighting system is based on the use of conventional low-voltage lampposts which are connected to the medium voltage grid of the campus via a BT/MT transformer.

Taking into account the potential of the geographical location, the communication technologies, generation and distribution of the electric power, and the analysis of the electrical consumption required by the different charges of the University Campus of Vigo, the implementation of an intelligent microgrid is designed. It is intended to function as an island that enables the connection to the general electrical system in case of failure of power cut, through a safety switch.

The advances in the research on Information and Communication Technologies (ICTs) ensure the quick and correct transmission of data among the different elements of the grid. That is why an installation of opticfibre communication is designed to enable a bidirectional flow of information among the different components, which will be managed by a communication, security and centralized control centre located next to the Teleco's Faculty, where the telecommunication network of the University Campus of Vigo is designed.

The microgrid will have a generation system of distributed energy able to satisfy the electrical demand, 
thus, enabling the energetic sustainability and independence of the University Campus of Vigo.

Every element is connected to the designed microgrid. This microgrid is mixed: it has a bus of DC and another one of AC, which are connected through an inverter. The different generation and consumption elements are connected to the bus of AC or DC according to its working parameters by means of transformers. Every element is in permanent bidirectional communication with the communication, security and control centre of the microgrid, through a centralized optic-fibre network.

\section{Consumption}

The energy transported by the medium voltage power line that crosses the campus is consumed by the charges, after being transformed into BT or MT in an independent transformation centre for each charge of the campus where the measure of the consumed energy made by the charge is also performed.

Once the analysis of the active and reactive energy consumption in the University Campus of Vigo has been made, we observe that there exists a constant consumption all throughout the year. The largest amount of consumption takes place in the faculties and educational centres, whose charges require a proper constant lighting, the connection of high energetic consumption hardwares, the heating which increases the consumption in winter, or the air conditioning system whose consumption increases in summer. The academic activity is intense from September to May, however, the centres are open even in August although the activity is less intense which provokes a decrease in the energy consumption.

Furthermore, the graphs on the evolution in the consumption illustrate that the higher intensity of energy demand is registered during the day between 9 AM and 3 $\mathrm{PM}$, since it is during this period when the academic activity takes place. During night-time, energy is mainly consumed by the low-voltage night lighting of the Campus, or by the lighting of the different sports facilities. Rightly, the rates for these charges of low-voltage consumption are the $3.0 \mathrm{~A}$ and the $2.1 \mathrm{DHA}$, with hourly discrimination that enable to get a lower price for the purchase of energy in the flat period with the rate 2.1 DHA, and in the off-peak hours with the rate 2.1 DHA and 3.0 A. This means that night-time rates penalize the offpeak hours consumption as the lighting of the campus is not necessary due to sunlight.

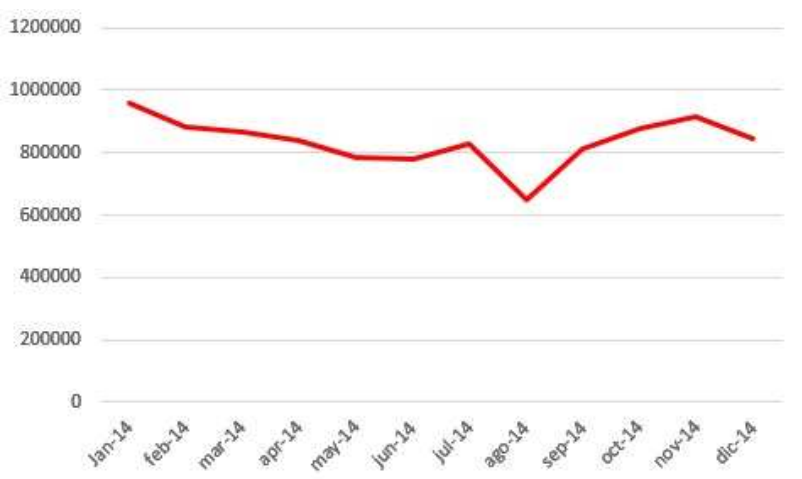

Fig. 1. Electrical consumption curve of the University of Vigo.

The yearly consumption of the University Campus of Vigo is very high, namely $10,045,902 \mathrm{kWh} /$ year, equivalent to the consumption of 2,598 4-member singlefamily homes.

Given this distribution of power consumption, and with the purpose of achieving an energetic autonomy and sustainability, it is necessary to install energy generation systems with production peaks between 9 AM and 3 PM. This is why the decision of installing generation systems of solar photovoltaic energy has been taken, along with a generation system of wind energy which enables the production of energy when the sunlight is not intense or inexistent, such is the case of the period between 6 PM and 9 PM, when the academic activity is still ongoing.

\section{Distributed generation}

The microgrid of the University Campus of Vigo is endowed with the capacity of functioning as an island, i.e. independently from the General Electrical System. Thus, the microgrid needs to have distributed generation elements of the necessary electricity to satisfy the high power consumption of the University Campus of Vigo.

\section{A. Photovoltaic solar energy}

In the microgrid of the University Campus of Vigo, the photovoltaic solar energy will be used as the main energy source. The transformation of the solar source into electric energy is carried out by the already installed photovoltaic solar panels.

The location [3] of the microgrid, $42^{\circ}$ latitude, presents excellent photovoltaic energy characteristics, from which the high incoming solar radiation has to be underscored since it enables the production of plenty of electric photovoltaic energy. 


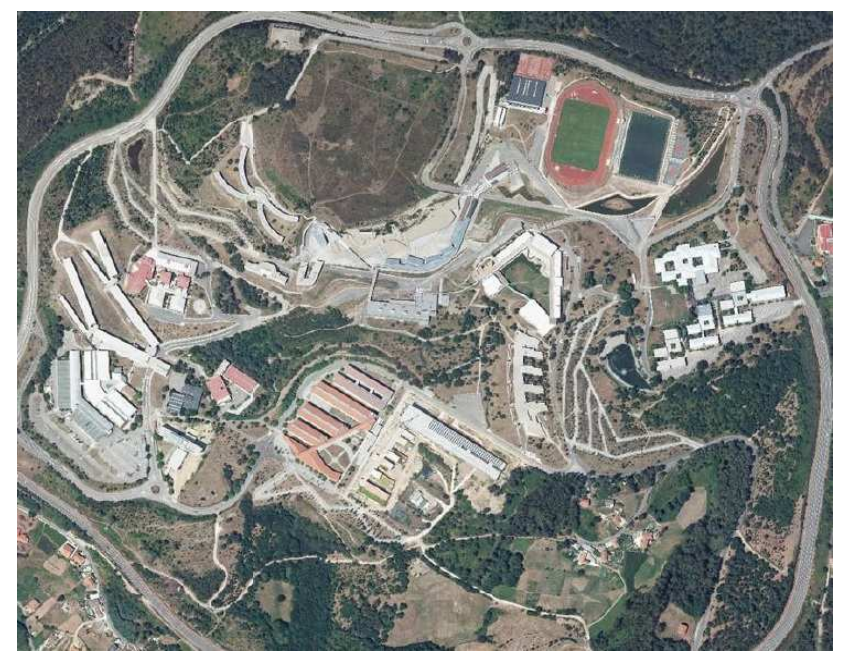

Fig. 2. The location of the University Campus of Vigo.

For producing electric power by means of photovoltaic solar panels, we will make use of the area of the main campus carparks. These are currently uncovered and unprotected from the adverse weather conditions, and without any intelligent parking management system.

To solve this, the construction of a cover for the main carparks of the campus is proposed, which in turn will be also used as support for the installed solar panels.

After a first scrutiny, using the solar panels of an important company and due to the large available area, 17,212 photovoltaic modules separated by 5 solar power farms will be installed. Each of them will have the following technical features:

Table I. - Technical characteristics of a solar panel.

\begin{tabular}{|c|c|}
\hline Maximun Output. & $295 \mathrm{~W}$ \\
\hline Open-Circuit Voltage. & $44.82 \mathrm{~V}$ \\
\hline Short-Circuit Current. & $8.78 \mathrm{~A}$ \\
\hline Maximun Output Voltage. & $36.23 \mathrm{~V}$ \\
\hline Maximun Output Current. & $8.14 \mathrm{~A}$ \\
\hline
\end{tabular}

Once the analysis of the panels and location has been made, the generators will be placed with a minimal distance of separation of $2.02 \mathrm{~m}$, an inclination angle of $30^{\circ}$, and a South orientation. Thus, thanks to this installation of $5,077.54 \mathrm{kWp}$, a yearly production of $8,258,000 \mathrm{kWh} /$ year is expected.

The peaks of photovoltaic production in the months of June, July, and August - reaching almost 1,000,000 kWh per month - show a sharp contrast with the low production in the months of January, February, November, and December. The problem is that these periods do not correspond with the level of energy consumption along the whole year.

The five solar power farms installed in the University Campus of Vigo generate electricity in the form of direct current. The produced electrical energy goes through a direct current transformer (DC transformer) which adapts and normalizes the generated energy to the grid conditions, tension, and power of the DC bus. Thus, this energy can be consumed by the DC charges, after going through a DC/AC inverter, and for the AC charges of the microgrid.

\section{B. Wind energy.}

Once the wind characterization of the location of the University Campus of Vigo has been done, we can conclude that the density of the wind is medium, and that the speed of the wind is low, even insufficient sometimes to generate energy. Therefore, only two wind turbines have been installed with the following technical features:

Table II. - Technical characteristics of the wind turbines.

\begin{tabular}{|c|c|}
\hline Rated Power. & $2,300 \mathrm{Kw}$. \\
\hline Rotor Diametre. & $71 \mathrm{~m}$. \\
\hline Rotor Height. & $98 \mathrm{~m}$. \\
\hline Rated Wind Speed. & $16 \mathrm{~m} / \mathrm{s}$. \\
\hline Cut-in Wind Speed. & $2 \mathrm{~m} / \mathrm{s}$. \\
\hline Cut-out Wind Speed. & $25 \mathrm{~m} / \mathrm{s}$. \\
\hline
\end{tabular}

The next step after having studied the wind of the area [4] and the wind turbines is to decide where to build the turbines. In this case, the chosen location has been an area of considerable height, free of obstacles, with a height superior to $16 \mathrm{~m}$ within the wind turbines area of influence, and with an orientation of $315^{\circ}$, with the purpose of taking advantage of the wind as much as possible.

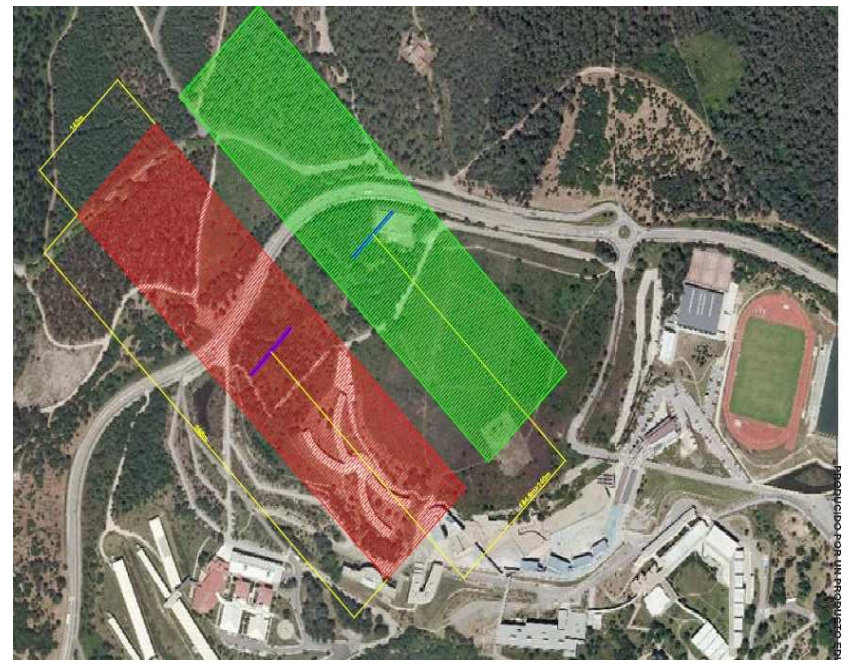

Fig. 3. The location of the wind turbines and their influence áreas.

Subsequently, we proceed to calculate of the electric power production that these wind turbines would generate monthly in this location, with that hub height, and that orientation. This calculation is made by means of probabilistic equations such as the Weibull distribution multiplied by the vector of the curve of power of the wind turbine.

The small wind farm of $4.6 \mathrm{MW}$ of the microgrid of the University Campus of Vigo will produce annually a total 
of 3,363,446.40 $\mathrm{kWh} /$ year. This wind energy production will focus mainly on its production in the months of January, February, and December, which are the months when the photovoltaic solar energy production will be very low.

The high powered wind turbines generate electricity in the form of alternating current at low voltage through a transformer located in the hub of the wind turbine, in order to decrease the loss due to the high-intensity transport and low voltage until the rate 0 of the wind turbine. This transformer is in charge of accommodating the generated electricity to the voltage conditions, grid power, and synchronization of the frequency of the generated wave with the wave of the AC bus of the microgrid of the University Campus of Vigo.

\section{Hydrogen Fuel Cells and energy storage system.}

The graph below illustrates the monthly energy balance between energy consumption and energy generation of the wind source and the solar source:

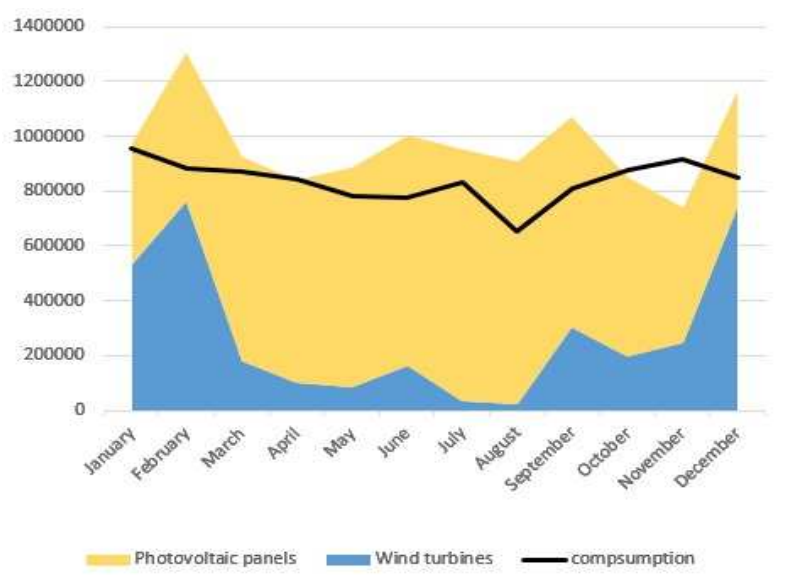

Fig. 4. Monthly energy balance.

It shows that in 10 months of the year 2014 energy overproduction takes place, whereas in the months of October and November the energy production is not enough to supply the consumption of the University Campus of Vigo.

This occurs because of the randomization of the generation sources of employed energies - the wind and photovoltaic solar energy - that do not enable a regulation of the energy generation in real time. This does not allow a correct adjustment between the consumption curve and the generation curve.

Thus, we find contrasts of moments of energy surplus and moments of power cuts in the microgrid.

These problems arise in a monthly balance as well as in an instant balance. Consequently, in order to avoid them it is necessary to install an auxiliary power generation system and an energy storage system which enables them to make use of energy overproduction when the energy production is not enough to supply the consumption.
Therefore, an installation has been designed by two electrolyzers, a hydrogen storage tank, and a hydrogen fuel cell.

The equipment that composes the system is the following:

1) Electrolyzers: Equipment in charge of the hydrogen production to be used as an energy vector. In 10 months of the year of 2014 (vid. Fig.4), the energy overproduction of the wind source and the photovoltaic solar source is used to power supply for the two electrolyzers, which through the electrolysis of water produce hydrogen. Thus, the energy surplus decreases and a greater control of the consumption curve of the University Campus of Vigo can be achieved.

Table III. - Technical characteristics of the electrolyzers.

\begin{tabular}{|c|c|}
\hline $\begin{array}{c}\text { Consumption } \\
\text { Electrolyzers. }\end{array}$ & $5.2 \mathrm{kWh} / \mathrm{Nm}^{3}$. \\
\hline Hydrogen production. & $30 \mathrm{Nm}^{3} / \mathrm{h}$. \\
\hline Electrical Consumption. & $156 \mathrm{~kW}$ \\
\hline
\end{tabular}

$\mathrm{H}_{2} \mathrm{O}+$ Electricity $\rightarrow \mathrm{H}_{2}+(1 / 2) \mathrm{O}_{2}$ (1)

2) Hydrogen storage system: The hydrogen generated by the electrolyzers when energy overproduction occurs is stored in a gas storage tank with a capacity for $26,400 \mathrm{Kg}$ of hydrogen, which is enough for this installation.

3) Hydrogen fuel cell [5]: Following an inverse process to the one of the electrolyzers - equation $1-$, the fuel cells generate electricity and water out of the oxygen and the hydrogen stored and generated when energy overproduction has occurred. Then, they make use of the hydrogen to generate electricity when the production of the wind sources is not enough to supply the consumption of the University Campus of Vigo. The usage of a hydrogen fuel cell of a nominal power of $1 \mathrm{MW}$ it makes to possible control the energy generation curve.

Installing the auxiliary power generation system and the energy storage system facilitates an optimal adjustment between the consumption curve and the energy production, thus, minimizing the power cuts and its underutilization.

This system will consume energy in form of $\mathrm{AC}$ current through the connection to the AC bus of the microgrid of the electrolyzers. The fuel cell will generate energy in the form of direct current. That is why it will be connected to the DC bus to take profit of the energy from the connected equipment to this bus or by going through a $\mathrm{DC} / \mathrm{AC}$ inverter from alternating current equipment. 


\section{Communication, security, control system of the microgrid of the University Campus of Vigo}

Through the ICTs technology, a Communication System of the microgrid based on a network of bidirectional communication of optic fibre has been designed. This would allow real time communication between the different elements of the microgrid.

The Communication System is a system centralized in a unity of security and control, which is in charge of processing the information obtained by the different sensors. Its purpose is predicting and proceeding in advance on the different elements of the microgrid in order to optimize the coordination and the collective operation of the different elements of the microgrid of the University Campus of Vigo.

The most important security and control systems designed in the microgrid are the following:

\section{A. Local controller.}

This microgrid has the capacity of functioning as an independent island as well as connected to the general electrical network. This would vary depending on the needs of the system or on the current energy policy favouring or not one functioning or another. The connection and disconnection of the microgrid to the general electrical network is made via a local switch installed in the substation of the campus. Thus, this exerts the function of protecting the microgrid from failures in the generation, conditioning, and synchronisation systems between the electrical system of the microgrid and the electrical system of the general electrical network.

\section{B. Central controller.}

Control unit of the microgrid system in charge of processing the information about the functioning of the microgrid, of predicting possible failures, and of proceeding on the different elements that compose the microgrid.

\section{Local controllers of the elements.}

Generation systems, charges, storage systems, or the different apps of the Smart Campus, all of them, have a local controller.

\section{Smart Campus}

Once the microgrid of the University Campus of Vigo energetically self-sufficient and sustainable - has been designed, we propose the installation of a series of intelligent apps that will transform the current University Campus of Vigo into a Smart Campus [7] that will improve the quality of life and studies of the campus users. Besides, it would improve the student atmosphere which would foster the competitiveness and cultural development of new entrepreneurs and companies. This will be done whithin a renewable, sustainable, and respectful manner within the environment atmosphere.

\section{A. Lighting systems. Solar luminaires.}

We propose to replace conventional lampposts with solar luminaires, thus, decreasing the electric energy consumption of the lighting system of the campus. The proposal consists of the installation of a selfconsumption lighting system, with more efficient lamps, with led technology, and photovoltaic energy generation system. Moreover, proximity sensors and intensity regulators will be installed to enable the system to make selective shutdowns from the central control system of the microgrid.

\section{B. Studies on energy efficiency.}

Another proposal is to carry out studies on energy efficiency in the 14 buildings of the campus, where electric energy consumption is higher. Besides, improvements in the insulation system of the buildings, changes and improvements on the performance of the conditioning equipment in the faculties will be also carried out in order to decrease the consumption of the final energy, to decrease $\mathrm{CO}_{2}$ emissions, and to obtain a level A energy certificate.

\section{Management of municipal solid waste.}

Introduction of intelligent containers for municipal solid waste with self-sufficient compactors, and remote capacity sensors which enable to optimization the collection process of the waste generated in the University Campus of Vigo.

\section{Charging points for electric vehicles.}

With the purpose of promoting the inclusion of the electric car in society and in everyday life of the campus users, we intend to install charging points for electric vehicles. In the main carparks of the campus, quick-charging points with solar panels will be installed, consequently this system realizes selfconsumption. In addition, three slow-charging points will be also installed in the campus, they will take up to 6 hours and self-sufficient as well.

\section{E. Intelligent carpark management system.}

Once the main carparks of the campus have been covered with the photovoltaic solar panels for generating distributed energy, we also propose an intelligent carpark management system. In every parking spot, occupancy sensors will be installed which will send information to the central system. This information will be displayed in information screens located at strategical places of the campus. These info screens will display information as regards to the level of occupation of the carparks to save time when searching for a slot to park, and also to decrease the traffic in the campus, and consequently decreasing the $\mathrm{CO}_{2}$ emissions.

\section{F. Intelligent marquees.}

As it happens in the main European Smart Cities, in a campus like this one where the access by bus is continuous, we propose to install self-sufficient intelligent marquees which are in constant communication and interaction with the user of the campus and with the central communication centre. 


\section{G. Electronic management.}

Implementation of intelligent systems to carry out administrative management of the university. Through mobile apps or websites, the different administrative operations of the university will be made. In this manner, management time will be reduced as well as storage spaces of physical documents or even the queues. As a consequence, the frustration of the users will be also reduced or eliminated, which will cause a considerable improvement of their quality of life.

\section{Conclusions}

In this way, the design of the Smart Campus of the University of Vigo concludes as a complex based on the energy self-sufficiency and sustainability, in respect of the natural environment.

To accomplish that purpose, an intelligent microgrid along with its elements that may function as an island or connected to the general electrical network is designed. In order to function as an island, the self-sufficiency of the System is required. To fulfil that purpose, two generation systems of renewable energies - mainly photovoltaic solar energy and wind energy - are installed. The randomness of these two energy sources prevents the functioning as an island since the demand curve cannot adjust to the consumption curve of the campus. Therefore, it is necessary to have a system that enables it to make this adjustment. That is why a system with two electrolyzers is designed, which enable it to control this consumption curve, taking advantage of the moments of energy overproduction. It is also necessary to design a storage system, and a hydrogen fuel cell that will be able to use the hydrogen produced at the moments when the energy production of the main sources is not enough to supply the high consumption of the campus, operating in this manner on the production curve of electricity.

With this energy generation system, we get energy autonomy from the system that joins to the rest of the elements of the microgrid which enable the proper working of the microgrid of the University Campus of Vigo as an island with a low underutilization of energy (Fig.7), and the implantation on it on the different apps of the Smart Campus.

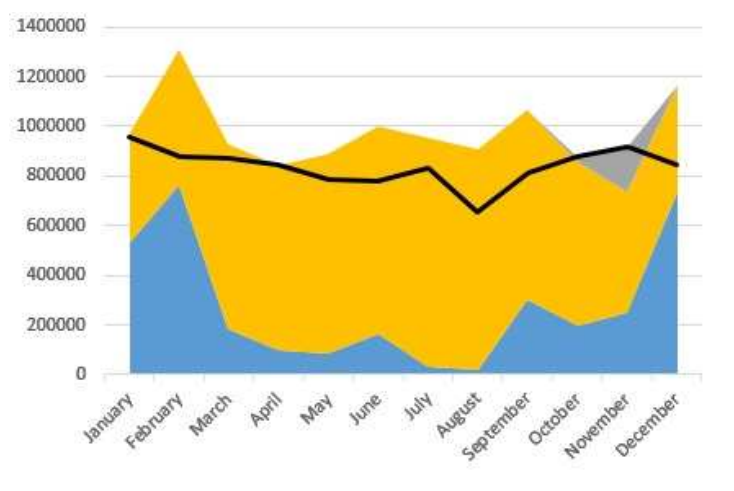

Fuel cells $=$ Photovoltaic panels $=$ Wind turbines - Comsuption

Fig. 5. Finally monthly energetic balance.

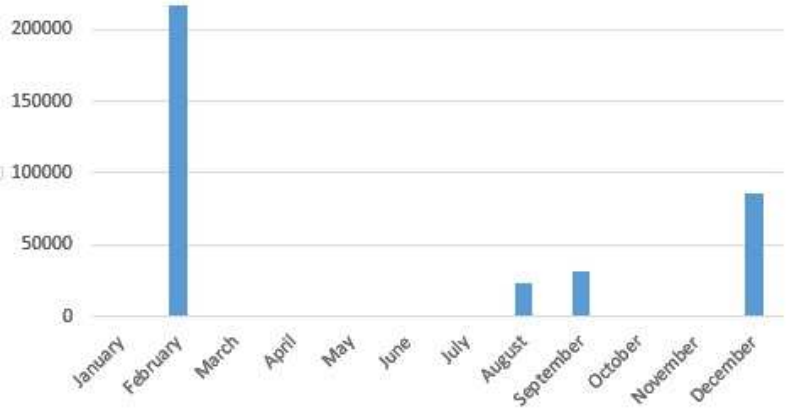

Fig. 6. Finally overproduction energy

For future research, it would be enlightening to study the profitability of the installation according to the current energy contexts, and also to elaborate an analysis of the budget and phases of implantation of the installation.

\section{References}

[1] J.J. Arenas, y M.J. Pantaleón, "Proyecto de Reordenación y Dotación de Servicios en el Campus Universitario de Vigo", Apia XXI S.A., July, 1997.

[2] C. Calo, y S. González, "Resumen Consumos de Energía Eléctrica Año 2014", Plan Suma, Oficina de Medio Ambiente (Universidade de Vigo), February, 2015.

[3] Visor SigPac [En Línea]. Ver coordenadas (X; Y): (523.580,70 ; 4.667.581,80). España: Fondo Español de Garantía Agraria. Informatic program. [Consulta: April, 2015].

[4] Matlab, "Matlab y las Energías Renovables", Universidad del País Vasco, [Consulta: Mayo de 2015], Document in HTML form accesible at this website: http://www.sc.ehu.es/sbweb/energiasrenovables/MATLAB/datos/viento/estadistica.html.

[5] J.I. San Martín, I. Zamora, J.J. San Martín, y V. Aperribay, "Avances en MicrogeneraciónEléctrica: Pilas de Combustible”, Departamento de Ingeniería Eléctrica, Escuela Universitaria de Ingeniería Técnica Industrial de Eibar (Universidad del País Vasco), Marzo, 2009.

[6] A. Sendín, "Redes y Sistemas para el Despliegue de una Red Eléctrica Inteligente”, Dirección de Sistemas de Control y Telecomunicaciones, Iberdrola, Septiembre, 2014.

[7] L.L. Moreno, y A. Gutiérrez, "Ciudades Inteligentes: oportunidades para generar soluciones sostenibles", Grupo estrategia, mercados regulación y política de la industria TIC, Cintel, Bogotá D. C. (Colombia), 2012. 